\title{
The normal ranges of selected acoustic rhinometry parameters depending on age and sex-component of standarization in nasal provocation test
}

\author{
Edyta Krzych-Fałta, Paulina Szczęsnowicz-Dąbrowska, Bolesław Samoliński, Antoni Grzanka, Oksana Wojas
}

Department of the Environmental Hazards Prevention and Allergology, Faculty of Health Sciences, Medical University of Warsaw, Warsaw, Poland

Adv Dermatol Allergol 2022; XXXIX (1): 171-181

DOI: https://doi.org/10.5114/ada.2021.105360

\begin{abstract}
Introduction: Acoustic rhinometry is a non-invasive method of measuring intranasal spaces. As one of the objective techniques for nasal patency, it plays a critical role in evaluating the nasal allergen challenge.

Aim: To establish the typical ranges of selected AR parameters for age and sex.

Material and methods: The study was conducted in a group of 583 randomly selected subjects ( 329 females and 254 males). Acoustic rhinometry was done before and $15 \mathrm{~min}$ after a two-time application of $0.1 \%$ solution of the decongestant xylomethazoline. The evaluated AR parameters (the cross-sectional area 1 (CSA-1) at the level of the isthmus nasi and the distance between the external nares and the isthmus nasi (dCSA-1)) were measured separately for both nasal cavities. Another evaluated parameter was the mean CSA measured $3 \mathrm{~cm}$ beyond CSA-1 on the AR curve (CSA-3).

Results: The site of the minimum CSA on the acoustic rhinometry curve in the study group was the second notch on the acoustic rhinometry curve (CSA-1), corresponding to the nasal isthmus. With increasing age of the subjects, we observed a systematic increase in nasal spaces. The difference between sexes reached statistical significance at the ages of 17 years and older.

Conclusions: The evaluated males show larger nasal cavity volumes than females. The difference between the sexes reaches statistical significance at older ages.
\end{abstract}

Key words: diagnostic techniques, respiratory system, nasal cavity, acoustic rhinometry, demography.

\section{Introduction}

Acoustic rhinometry (AR) is an assessment technique involving measuring sound waves that are reflected after being emitted into the nasal cavity. The sound waves reflected off the evaluated intranasal structures are collected via a microphone and converted into electrical impulses. AR results are in the form of a graph illustrating the individual cross-sectional areas of the nasal cavity at various distances from the nostrils. As a technique for objectively assessing nasal patency, AR is widely used in nasal allergy diagnostics, on the other hand, there are discrepant literature reports as to the ways of interpreting rhinometric curves due to the multitude of data obtained during this examination [1-6]. In the group of objective techniques, nasal examinations play an important role in the evaluation of the nasal allergen challenge test. The most commonly assessed AR param- eters of nasal obstruction are the minimum cross-sectional area (MCA) of the nasal cavity and the cross-sectional areas at $3.3 \mathrm{~cm}$ and $4.0 \mathrm{~cm}$ (CA3.3; CA4.0) from the nosepiece. These parameters have always been the key reference points on the manometric curve, with the MCA having the greatest impact on nasal obstruction, and CA3.3 and CA4.0 being the most reactive sites following the application of a decongestant. In healthy individuals, the MCA is generally located at the isthmus nasi, which corresponds to the I-notch on the rhinometry curve. A posteriorly shifted MCA indicates either an oedematous nasal mucosa (in which case administration of a decongestant restores a more anterior location of the MCA, at the isthmus nasi) or a deviated nasal septum (in which case mucosal decongestion has no effect on AR results).

The key causes of discrepancies in the rhinometric curve analysis are a lack of precise, generally accepted

Address for correspondence: Edyta Krzych-Fałta PhD, Department of the Environmental Hazards Prevention and Allergology, Faculty of Health Sciences, Medical University of Warsaw, 1a Banacha St, 02-097 Warsaw, Poland, phone: +48 22599 10 40, e-mail: e.krzych@gmail.com Received: 16.12 .2020 , accepted: 21.12.2020. 
definitions of anterior nasal structures, such as the nasal valve, isthmus nasi, head of the inferior turbinate; the use of various nasal adapters and rhinometers; a lack of universally defined beginning of the nasal cavity on a rhinometry curve; the scant number of reports comparing the location of rhinometry curve notches with the location of the corresponding nasal structures; and discrepancies between the course of the acoustic axis in the nasal cavity and the actual cross-sectional areas [7]. Importantly, the lack of reference AR values (obtained in a healthy population) poses problems in interpreting $A R$ results obtained in study populations with nasal allergies.

\section{Aim}

The purpose of the study was to extend the scope of standardized values for cross-sectional areas of the nasal cavity measured via AR in an evaluated Polish population, by stratifying them by age and sex. Ours is the first representative study of this kind which deals with such a wide variety of AR parameters in the evaluated population and takes into account patients' age in the wide range of 6-17 years and older. Earlier studies on AR in paediatric patients had been conducted in small study populations. The obtained values had been typically averaged for the entire study population of children of various ages. Analyses of such averaged data preclude determining normal values of rhinometric parameters in individual age groups.

\section{Material and methods}

The study population comprised 583 randomly selected individuals living in a large metropolitan area of Warsaw (329 (59\%) females and 254 (41\%) males). The mean age of study subjects was 15.3 years, ranging from 6 to 76 years. Only healthy individuals (i.e. those with no symptoms of nasal obstruction and no significant nasal pathology detected on physical examination) were included in the study. The following age groups were established: $6-8$ years, 9-10 years, $11-12$ years, $13-14$ years, $15-16$ years, and $\geq 17$ years. The selection of these age groups was aimed to ensure a comparable number of study subjects (30 or more) in each evaluated group. Due to the relatively low proportion of adult subjects (62 individuals over 18 years of age), all adults were amassed into the single age range of $\geq 17$ years. Each of these age groups was analysed separately for either sex. An AR assessment (Rhinometrics SRE 2000 A/S, Lynge, Denmark, with the use of anatomic nasal adapters) was conducted with the mucosa both in its physiological condition and 15 min after intranasal administration of a decongestant (0.1\% Xylomethazoline). The decongestant, in the form of an aerosol, was administered twice at a 5-minute interval. The examination was conducted 10 min after the second administration. Inclusion criteria: age from 6 to 80 years, nasal scaffolding and internal structures without deformities; possibly natural nasal septum deviation rated as grade I in the endoscopic turbinoseptal (T/S) classification. Exclusion criteria: a history of rhinoplasty, injury significantly altering the nasal scaffolding and intranasal structures, acute upper respiratory tract infection, symptomatic rhinitis; nasal or nasopharyngeal tumours; nasal polyps; pregnancy; mental disorders; and poor subject cooperation. In order to ultimately establish the normal ranges for individual AR-curve parameters, we analysed the AR results of individuals with no evidence of nasal septum deviation in anterior rhinoscopy $(n=444)$. The 194 individuals excluded from the analysis showed rhinoscopic evidence of slight nasal septum deviation (rated as grade II in the T/S classification; i.e. with the anterior attachment of the middle turbinate partially covered by a laterally deviated nasal septum). The analysed age groups were not identical in terms of the number of assessed individuals $(n)$. In the case when a single measured parameter was missing, we did not exclude that individual from the analysis. Excluding from analysis, all data obtained from a given individual only because a single parameter was unavailable would have dramatically reduced the amount of data available for analysis. However, while we calculated statistical significance (while comparing the data obtained in females and males), the analysed data were compared in pairs; hence, the number of analysed patients for each given pair of data was smaller for some parameters.

Each subject underwent AR several times on both sides of the nose in short time intervals to produce several (from 2 to 6) rhinometry curves (Table 1). Preparation of the collected data for the analysis required the selection of the most representative measurement from this data set. We developed an algorithm selecting the so-called "central" curve according to the idea of selecting from the middle of a data set. The parameter that determined curve selection was cross-sectional area 3 (CSA-3) (Figure 1), i.e. the averaged CSA measured $3 \mathrm{~cm}$ deeper in the nasal cavity than CSA-1. If there were an odd number of rhinometric curves in the given data set, the selected central curve was the one with the median CSA-3 value. On the other hand, if there were an even number of rhinometry curves in the given data set, there are two median values. If there were only exactly two curves in the set or the difference between the CSA-3 values of the two candidate curves was very small (less than 5\%), then one of them was picked randomly. With at least four significantly scattered curves, we exclude one of the extreme curves, causing the cardinality of the set to be odd. The excluded extreme (minimal or maximal CSA-3) was that curve that is furthest from the two central ones. Also here, we used the absolute difference of CSA-3 as the comparison criterion.

The following points on the AR curves were considered in our analysis: CSA-1 (the lowest value of the I-notch (the second notch on the AR curve corresponding to the region of the nasal valve (isthmus nasi)), CSA-3 
Table 1. The number $(n)$ of acoustic rhinometry curves (stratified by subjects' age and sex) used to measure CSA-1, CSA-3 and dCSA-1 on either side of the nose before and after decongestant administration

\begin{tabular}{|c|c|c|c|c|c|c|c|c|}
\hline \multirow[t]{2}{*}{ Age [years] } & \multicolumn{4}{|c|}{ Females $(n)$} & \multicolumn{4}{|c|}{ Males ( $n$ ) } \\
\hline & LB & RB & LA & RA & LB & RB & LA & RA \\
\hline \multicolumn{9}{|l|}{ CSA-1: } \\
\hline $6-8$ & 52 & 49 & 44 & 48 & 36 & 39 & 35 & 37 \\
\hline $9-10$ & 36 & 35 & 32 & 34 & 25 & 22 & 21 & 24 \\
\hline $11-12$ & 36 & 35 & 35 & 34 & 39 & 41 & 40 & 40 \\
\hline $13-14$ & 26 & 26 & 26 & 26 & 40 & 40 & 40 & 40 \\
\hline $15-16$ & 44 & 44 & 43 & 43 & 29 & 30 & 30 & 30 \\
\hline $17-18$ & 24 & 24 & 23 & 23 & 9 & 9 & 9 & 9 \\
\hline$>18$ & 26 & 28 & 26 & 28 & 9 & 9 & 9 & 9 \\
\hline Total population & 244 & 241 & 229 & 236 & 187 & 190 & 184 & 189 \\
\hline \multicolumn{9}{|l|}{ CSA-3: } \\
\hline $6-8$ & 52 & 49 & 44 & 48 & 36 & 39 & 35 & 37 \\
\hline $9-10$ & 36 & 35 & 32 & 34 & 25 & 22 & 21 & 24 \\
\hline $11-12$ & 36 & 35 & 35 & 34 & 39 & 41 & 40 & 40 \\
\hline $13-14$ & 26 & 26 & 26 & 26 & 40 & 40 & 40 & 40 \\
\hline $15-16$ & 44 & 44 & 43 & 43 & 29 & 30 & 30 & 30 \\
\hline $17-18$ & 24 & 24 & 23 & 23 & 9 & 9 & 9 & 9 \\
\hline$>18$ & 26 & 28 & 26 & 28 & 9 & 9 & 9 & 9 \\
\hline Total population & 244 & 241 & 229 & 236 & 187 & 190 & 184 & 189 \\
\hline \multicolumn{9}{|l|}{ dCSA-1: } \\
\hline $6-8$ & 44 & 44 & 39 & 44 & 28 & 31 & 26 & 31 \\
\hline $9-10$ & 31 & 31 & 31 & 34 & 20 & 22 & 20 & 21 \\
\hline $11-12$ & 35 & 35 & 32 & 34 & 35 & 38 & 35 & 33 \\
\hline $13-14$ & 26 & 26 & 24 & 26 & 38 & 36 & 36 & 38 \\
\hline $15-16$ & 44 & 44 & 43 & 43 & 28 & 30 & 30 & 30 \\
\hline $17-18$ & 23 & 24 & 22 & 23 & 9 & 9 & 9 & 9 \\
\hline$>18$ & 26 & 24 & 26 & 25 & 9 & 9 & 9 & 9 \\
\hline Total population & 229 & 228 & 217 & 229 & 167 & 175 & 165 & 171 \\
\hline
\end{tabular}

CSA-1 - cross-sectional area 1 (at notch 1 along the acoustic rhinometry curve, dCSA-1-distance between the anterior nares and CSA-1, LA - left side of the nose after decongestion, $L B$ - left side of the nose before decongestion, $R A$ - right side of the nose after decongestion, $R B$-right side of the nose before decongestion.

(the mean cross-sectional area of the nasal cavity at $3 \mathrm{~cm}$ beyond the 1 -notch) and the distance from the anterior nares to the isthmus nasi (dCSA-1). Since not all AR curves had a discernible C-notch (CSA-2), we omitted this parameter from our analysis and analysed CSA-3 instead. According to a recommendation by Hilberg $[8,9]$, the AR values measured separately for the right and left nasal cavities were averaged to minimize the risk of the nasal cycle affecting the final result of this study.

This study had been approved by the Institutional Review Board at the Medical University of Warsaw.

\section{Statistical analysis}

Pearson's $\chi^{2}$ test was used in the statistical analysis, with $p$-values of $<0.05$ considered to be statistically significant.

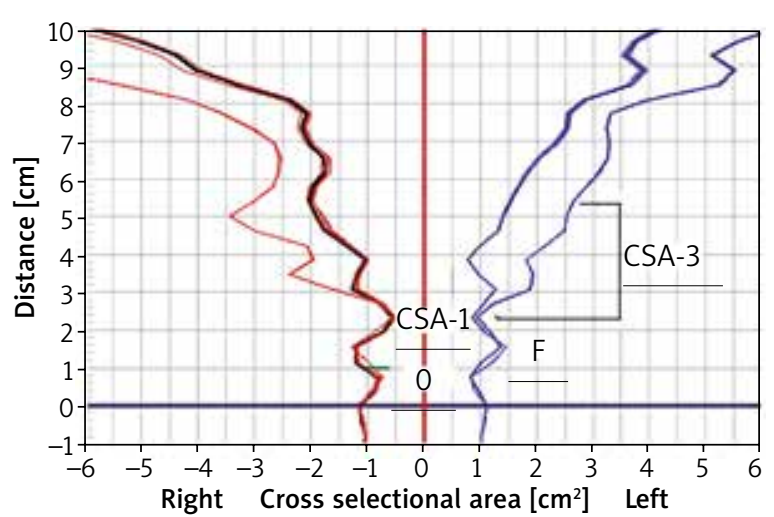

Figure 1. Location of the analysed notches CSA-1, CSA-3 on acoustic rhinometry curves 


\section{Results}

Our attempt at parametrization of the lowest points on the rhinometry curve (CSA-1, CSA-3) and the distance between the anterior nares and the isthmus nasi (dCSA-1) demonstrated considerably greater cross-sectional areas in the male subpopulation (Tables 2-4). Moreover, the increase in AR parameter values in the male subpopulation over time was greater than that in the female subpopulation. We have presented the measured AR parameters stratified by age and sex (Figures 2-4).
Normal ranges of CSA-1 values in the females and males from the individual age groups

As shown in Table 2, we observed a gradual increase in the mean CSA-1 value, with significant differences between the study groups noticeable at the ages of 17 years and older. Between the ages of 6 and $\geq 18$ years, in the - subpopulation of females the mean CSA-1 values ranged from 0.38 to $0.49 \mathrm{~cm}^{2}$ (right side) and from 0.37 to $0.51 \mathrm{~cm}^{2}$ (left side), respectively, whereas in the male subpopulation CSA-1 values ranged from 0.39

Table 2. Mean normal CSA-1 values (stratified by subjects' age and sex) measured on either side of the nose before and after administration of a decongestant

\begin{tabular}{|c|c|c|c|c|c|}
\hline \multirow[t]{2}{*}{ Age [years] } & \multicolumn{2}{|c|}{ Females } & \multicolumn{2}{|c|}{ Males } & \multirow{2}{*}{$\begin{array}{l}\text { Statistical } \\
\text { significance }\end{array}$} \\
\hline & Mean $\left[\mathrm{cm}^{2}\right]$ & $\mathrm{SD}\left[\mathrm{cm}^{2}\right]$ & Mean $\left[\mathrm{cm}^{2}\right]$ & $\mathrm{SD}\left[\mathrm{cm}^{2}\right]$ & \\
\hline \multicolumn{6}{|c|}{ CSA-1 on the left side of the nose before a decongestant: } \\
\hline $6-8$ & 0.37 & 0.09 & 0.37 & 0.08 & NS \\
\hline $9-10$ & 0.38 & 0.07 & 0.35 & 0.10 & NS \\
\hline $11-12$ & 0.44 & 0.10 & 0.42 & 0.13 & NS \\
\hline $13-14$ & 0.52 & 0.14 & 0.47 & 0.12 & NS \\
\hline $15-16$ & 0.53 & 0.12 & 0.54 & 0.11 & NS \\
\hline $17-18$ & 0.44 & 0.12 & 0.63 & 0.10 & $p<0.00001$ \\
\hline$>18$ & 0.51 & 0.08 & 0.61 & 0.17 & $p<0.02$ \\
\hline \multicolumn{6}{|c|}{ CSA-1 on the right side of the nose before a decongestant: } \\
\hline $6-8$ & 0.38 & 0.12 & 0.39 & 0.16 & NS \\
\hline $9-10$ & 0.38 & 0.07 & 0.38 & 0.12 & NS \\
\hline $11-12$ & 0.47 & 0.10 & 0.42 & 0.09 & NS \\
\hline $13-14$ & 0.49 & 0.10 & 0.44 & 0.12 & NS \\
\hline $15-16$ & 0.52 & 0.12 & 0.59 & 0.18 & $p<0.05$ \\
\hline $17-18$ & 0.48 & 0.13 & 0.63 & 0.18 & $p<0.002$ \\
\hline$>18$ & 0.49 & 0.14 & 0.55 & 0.21 & NS \\
\hline \multicolumn{6}{|c|}{ CSA-1 on the left side of the nose after a decongestant: } \\
\hline $6-8$ & 0.39 & 0.08 & 0.39 & 0.08 & NS \\
\hline $9-10$ & 0.41 & 0.08 & 0.40 & 0.08 & NS \\
\hline $11-12$ & 0.49 & 0.10 & 0.47 & 0.11 & NS \\
\hline $13-14$ & 0.54 & 0.12 & 0.51 & 0.12 & NS \\
\hline $15-16$ & 0.56 & 0.11 & 0.59 & 0.13 & NS \\
\hline $17-18$ & 0.52 & 0.14 & 0.67 & 0.10 & $p<0.001$ \\
\hline$>18$ & 0.54 & 0.09 & 0.70 & 0.10 & $p<0.0005$ \\
\hline \multicolumn{6}{|c|}{ CSA-1 on the right side of the nose after a decongestant: } \\
\hline $6-8$ & 0.41 & 0.13 & 0.40 & 0.14 & NS \\
\hline $9-10$ & 0.42 & 0.14 & 0.42 & 0.11 & NS \\
\hline $11-12$ & 0.49 & 0.09 & 0.45 & 0.10 & NS \\
\hline $13-14$ & 0.51 & 0.12 & 0.45 & 0.10 & $p<0.05$ \\
\hline $15-16$ & 0.56 & 0.11 & 0.63 & 0.17 & $p<0.05$ \\
\hline $17-18$ & 0.53 & 0.14 & 0.64 & 0.19 & $p<0.02$ \\
\hline$>18$ & 0.57 & 0.30 & 0.67 & 0.20 & $p<0.002$ \\
\hline
\end{tabular}

CSA-1 - cross-sectional area 1 (isthmus nasi), NS - not statistically significant, SD - standard deviation. 
to $0.55 \mathrm{~cm}^{2}$ (right side) and from 0.37 to $0.61 \mathrm{~cm}^{2}$ (left side), respectively.

Normal ranges of CSA-3 values in the females and males from the individual age groups

The analysed point on the rhinometry curve (CSA-3) corresponds to the level of the middle portion of the inferior turbinate and the anterior portion of the middle turbinate. This nasal region showed the most pronounced reaction to a nasal decongestant (resulting in the greatest alterations in the corresponding section of the AR curve). We observed a gradual increase in CSA-3 values (analogous to that seen in CSA-1 values) over the evaluated age range. Namely, mean CSA-3 values in the female subpopulation ranged from 0.69 to $1.19 \mathrm{~cm}^{2}$ (right side) and from 0.61 to $1.26 \mathrm{~cm}^{2}$ (left side). The CSA-1 values in the male subpopulation were higher, and ranged from 0.80 to $1.31 \mathrm{~cm}^{2}$ (right side) and from 0.71 to $1.37 \mathrm{~cm}^{2}$ (left

Table 3. Mean normal CSA-3 values (stratified by subjects' age and sex) measured on either side of the nose before and after administration of a decongestant

\begin{tabular}{|c|c|c|c|c|c|}
\hline \multirow[t]{2}{*}{ Age [years] } & \multicolumn{2}{|c|}{ Female } & \multicolumn{2}{|c|}{ Male } & \multirow{2}{*}{$\begin{array}{l}\text { Statistical } \\
\text { significance }\end{array}$} \\
\hline & Mean $\left[\mathrm{cm}^{2}\right]$ & $\mathrm{SD}\left[\mathrm{cm}^{2}\right]$ & Mean $\left[\mathrm{cm}^{2}\right]$ & $\mathrm{SD}\left[\mathrm{cm}^{2}\right]$ & \\
\hline \multicolumn{6}{|c|}{ CSA-3 on the left side of the nose before a decongestant: } \\
\hline $6-8$ & 0.67 & 0.19 & 0.71 & 0.17 & NS \\
\hline $9-10$ & 0.77 & 0.20 & 0.76 & 0.21 & NS \\
\hline $11-12$ & 0.86 & 0.24 & 0.86 & 0.21 & NS \\
\hline $13-14$ & 0.97 & 0.20 & 0.89 & 0.25 & NS \\
\hline $15-16$ & 0.99 & 0.22 & 1.03 & 0.24 & NS \\
\hline $17-18$ & 0.94 & 0.29 & 1.34 & 0.28 & $p<0.000005$ \\
\hline$>18$ & 1.26 & 0.29 & 1.37 & 0.45 & NS \\
\hline \multicolumn{6}{|c|}{ CSA-3 on the right side of the nose before a decongestant: } \\
\hline $6-8$ & 0.69 & 0.25 & 0.80 & 0.25 & $p<0.05$ \\
\hline $9-10$ & 0.77 & 0.22 & 0.78 & 0.18 & NS \\
\hline $11-12$ & 0.86 & 0.22 & 0.87 & 0.23 & NS \\
\hline $13-14$ & 0.95 & 0.18 & 0.99 & 0.30 & NS \\
\hline $15-16$ & 1.04 & 0.23 & 1.19 & 0.35 & $p<0.02$ \\
\hline $17-18$ & 1.01 & 0.26 & 1.28 & 0.36 & $p<0.005$ \\
\hline$>18$ & 1.19 & 0.28 & 1.31 & 0.30 & NS \\
\hline \multicolumn{6}{|c|}{ CSA-3 on the left side of the nose after a decongestant: } \\
\hline $6-8$ & 0.88 & 0.15 & 0.93 & 0.19 & NS \\
\hline $9-10$ & 1.00 & 0.19 & 0.96 & 0.17 & NS \\
\hline $11-12$ & 1.04 & 0.21 & 1.07 & 0.19 & NS \\
\hline $13-14$ & 1.27 & 0.22 & 1.21 & 0.24 & NS \\
\hline $15-16$ & 1.27 & 0.27 & 1.32 & 0.28 & NS \\
\hline $17-18$ & 1.41 & 0.35 & 1.61 & 0.38 & $p<0.05$ \\
\hline$>18$ & 1.44 & 0.25 & 1.75 & 0.46 & $p<0.002$ \\
\hline \multicolumn{6}{|c|}{ CSA-3 on the right side of the nose after a decongestant: } \\
\hline $6-8$ & 0.84 & 0.21 & 0.95 & 0.22 & NS \\
\hline $9-10$ & 0.96 & 0.22 & 0.95 & 0.17 & NS \\
\hline $11-12$ & 1.02 & 0.21 & 1.05 & 0.22 & NS \\
\hline $13-14$ & 1.27 & 0.24 & 1.29 & 0.26 & NS \\
\hline $15-16$ & 1.26 & 0.24 & 1.38 & 0.35 & NS \\
\hline $17-18$ & 1.48 & 0.30 & 1.52 & 0.30 & NS \\
\hline$>18$ & 1.46 & 0.38 & 1.66 & 0.34 & $p<0.05$ \\
\hline
\end{tabular}

CSA-3 - cross-sectional area measured $3 \mathrm{~cm}$ beyond CSA-1 (isthmus nasi), NS - not statistically significant, SD - standard deviation. 
Table 4. Mean normal distance between the anterior nares and isthmus nasi (dCSA-1) (stratified by subjects' age and sex) measured on either side of the nose before and after administration of a decongestant

\begin{tabular}{|c|c|c|c|c|c|}
\hline \multirow[t]{2}{*}{ Age [years] } & \multicolumn{2}{|c|}{ Female } & \multicolumn{2}{|c|}{ Male } & \multirow{2}{*}{$\begin{array}{l}\text { Statistical } \\
\text { significance }\end{array}$} \\
\hline & Mean $\left[\mathrm{cm}^{2}\right]$ & $\mathrm{SD}\left[\mathrm{cm}^{2}\right]$ & Mean $\left[\mathrm{cm}^{2}\right]$ & $\mathrm{SD}\left[\mathrm{cm}^{2}\right]$ & \\
\hline \multicolumn{6}{|c|}{ dCSA-1 on the left side of the nose before a decongestant: } \\
\hline $6-8$ & 1.18 & 0.24 & 1.28 & 0.33 & NS \\
\hline $9-10$ & 1.28 & 0.18 & 1.32 & 0.31 & NS \\
\hline $11-12$ & 1.38 & 0.23 & 1.33 & 0.24 & NS \\
\hline $13-14$ & 1.38 & 0.19 & 1.45 & 0.27 & NS \\
\hline $15-16$ & 1.49 & 0.24 & 1.62 & 0.27 & $p<0.05$ \\
\hline $17-18$ & 1.51 & 0.20 & 1.68 & 0.19 & NS \\
\hline$>18$ & 1.58 & 0.33 & 1.80 & 0.26 & NS \\
\hline \multicolumn{6}{|c|}{ dCSA-1 on the right side of the nose before a decongestant: } \\
\hline $6-8$ & 1.12 & 0.25 & 1.19 & 0.15 & NS \\
\hline $9-10$ & 1.27 & 0.20 & 1.21 & 0.21 & NS \\
\hline $11-12$ & 1.32 & 0.20 & 1.30 & 0.20 & NS \\
\hline $13-14$ & 1.36 & 0.19 & 1.38 & 0.21 & NS \\
\hline $15-16$ & 1.45 & 0.18 & 1.55 & 0.19 & $p<0.05$ \\
\hline $17-18$ & 1.41 & 0.19 & 1.73 & 0.28 & $p<0001$ \\
\hline$>18$ & 1.53 & 0.25 & 1.75 & 0.21 & $p<0.02$ \\
\hline \multicolumn{6}{|c|}{ dCSA-1 on the left side of the nose after a decongestant: } \\
\hline $6-8$ & 1.08 & 0.18 & 1.13 & 0.19 & NS \\
\hline $9-10$ & 1.11 & 0.22 & 1.14 & 0.17 & NS \\
\hline $11-12$ & 1.21 & 0.20 & 1.30 & 0.22 & NS \\
\hline $13-14$ & 1.28 & 0.17 & 1.35 & 0.23 & NS \\
\hline $15-16$ & 1.33 & 0.19 & 1.52 & 0.28 & $p<0.002$ \\
\hline $17-18$ & 1.38 & 0.19 & 1.59 & 0.24 & $p<0.01$ \\
\hline$>18$ & 1.51 & 0.21 & 1.74 & 0.30 & $p<0.02$ \\
\hline \multicolumn{6}{|c|}{ dCSA-1 on the right side of the nose after a decongestant: } \\
\hline $6-8$ & 1.10 & 0.18 & 1.19 & 0.24 & NS \\
\hline $9-10$ & 1.23 & 0.17 & 1.18 & 0.16 & NS \\
\hline $11-12$ & 1.26 & 0.19 & 1.26 & 0.21 & NS \\
\hline $13-14$ & 1.33 & 0.19 & 1.38 & 0.20 & NS \\
\hline $15-16$ & 1.37 & 0.19 & 1.47 & 0.22 & $p<0.05$ \\
\hline $17-18$ & 1.39 & 0.18 & 1.63 & 0.25 & $p<0.005$ \\
\hline$>18$ & 1.50 & 0.26 & 1.72 & 0.19 & $p<0.02$ \\
\hline
\end{tabular}

$d C S A-1$ - distance between anterior nares and cross-sectional area 1 (isthmus nasi), NS - not statistically significant; SD - standard deviation.

side). Nasal patency in the evaluated study groups was significantly greater following administration of a topical nasal decongestant.

Normal ranges of the distance between the external nares and the isthmus nasi (dCSA-1) in the females and males form the individual age groups

As before, along with the observed changes in cross-sectional areas of the nasal cavity, we observed an increase in the distance from the external nares to isthmus nasi (dCSA-1) over the evaluated age range. In females, that distance increased from 1.12 to $1.53 \mathrm{~cm}^{2}$ (right side) and from 1.18 to $1.58 \mathrm{~cm}^{2}$ (left side). In males, it increased from 1.19 to $1.74 \mathrm{~cm}^{2}$ (right side) and 1.28 to $1.80 \mathrm{~cm}^{2}$ (left side).

The location of the minimal cross-sectional area (the greatest narrowing of the nasal cavity) along the AR curve in healthy individuals

Prior to administering a topical decongestant, AR curves of the left and right nasal cavity showed the small- 


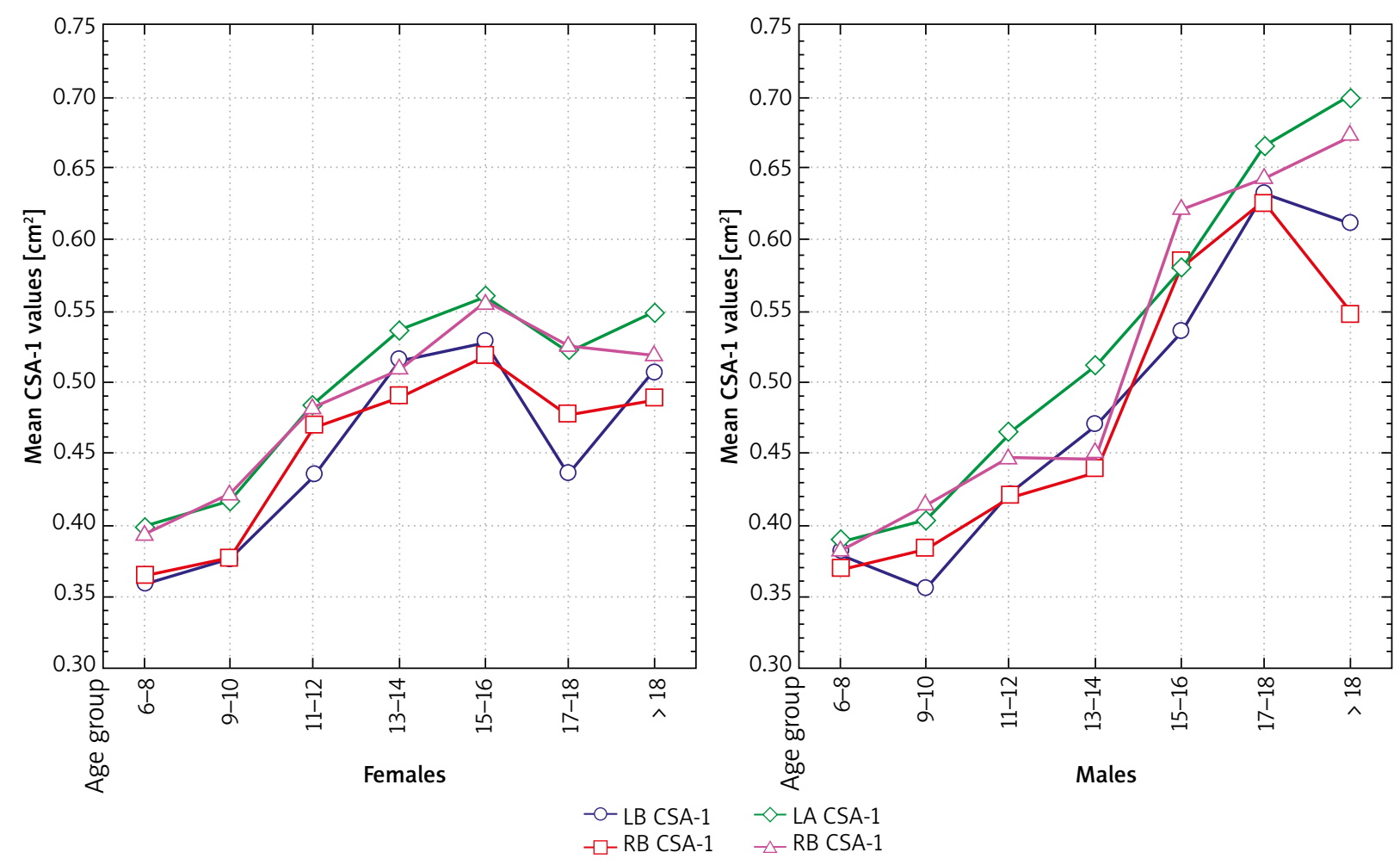

CSA-1 - cross-sectional area 1 (isthmus nasi), LA - left side of the nose after a decongestant, $L B$ - left side of the nose before a decongestant, $R A$ - right side of the nose after a decongestant, $R B$ - right side of the nose before a decongestant.

Figure 2. Mean CSA-1 values before and after administration of a decongestant in healthy individuals (with no deviated nasal septum); data stratified by age and sex
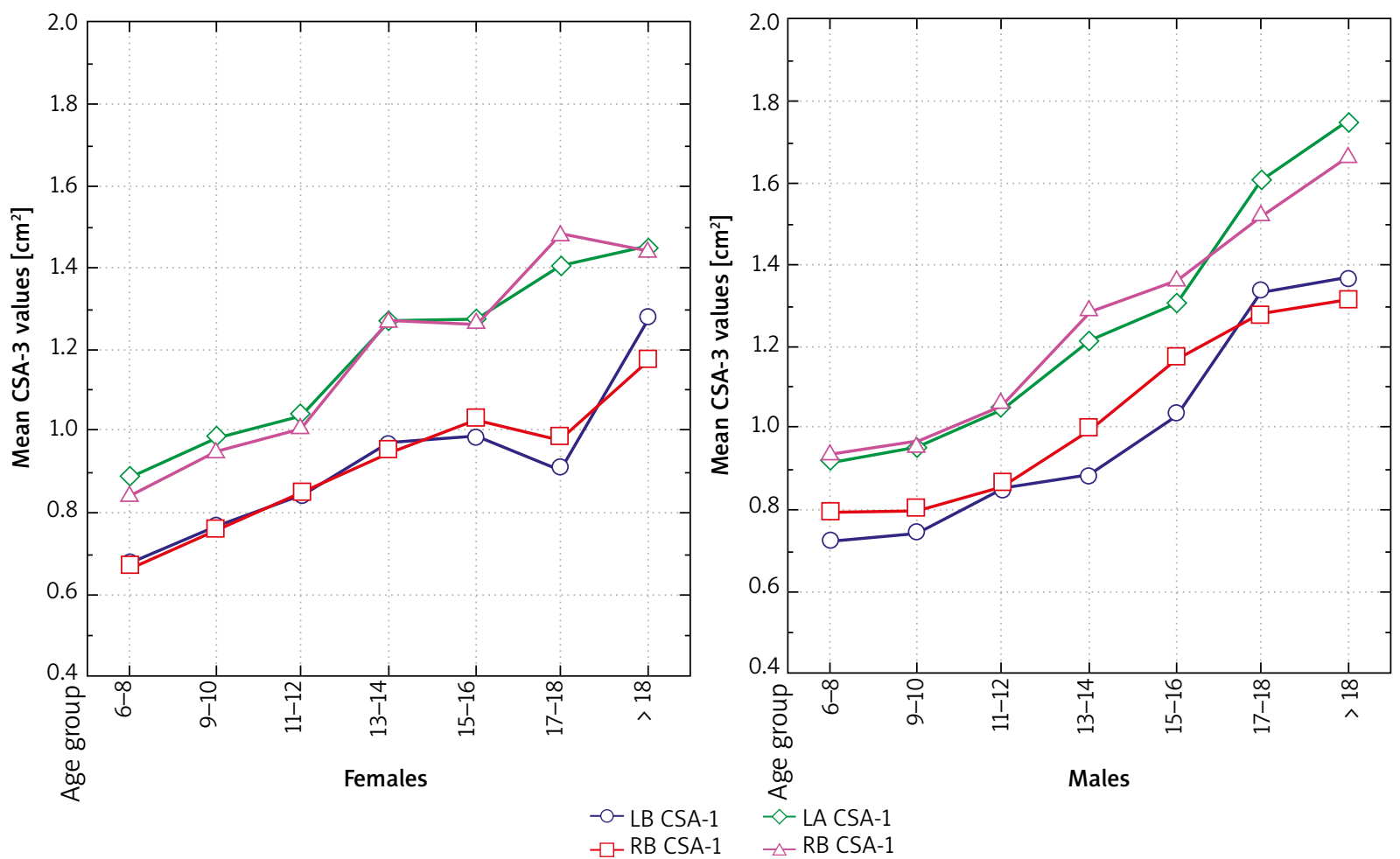

CSA-3 - cross-sectional area located $3 \mathrm{~cm}$ beyond CSA-1 (isthmus nasi) on an AR curve, $L A$ - left side of the nose after a decongestant, $L B$ - left side of the nose before a decongestant, $R A$ - right side of the nose after a decongestant, RB-right side of the nose before a decongestant.

Figure 3. Mean CSA-3 values before and after administration of a decongestant in healthy individuals (with no deviated nasal septum); data stratified by age and sex 


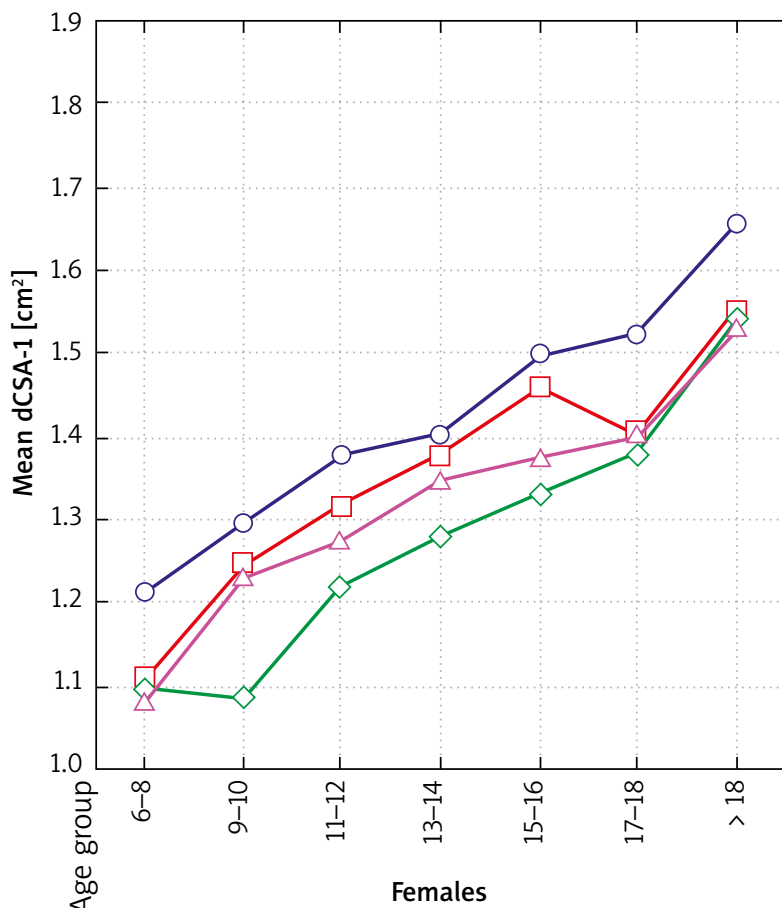

- - LB $0 \mathrm{~cm}-\mathrm{CSA}-1$ $\neg-$ RB 0 cm-CSA-1

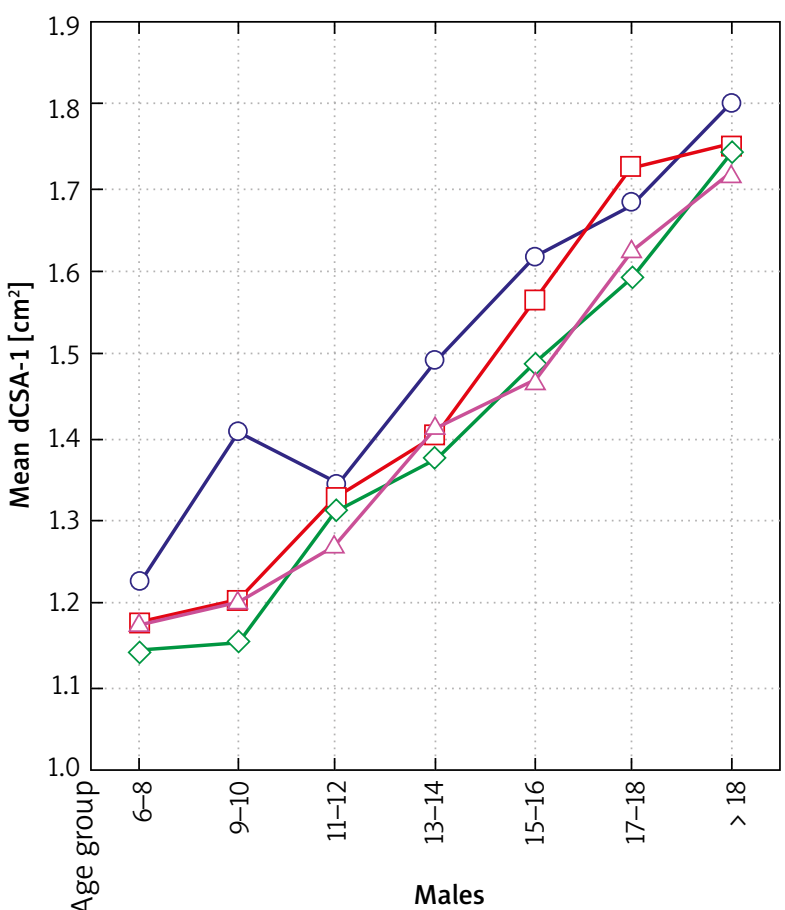

$\prec$ LA 0 cm-CSA-1

$\triangle$ RA $0 \mathrm{~cm}-\mathrm{CSA}-1$

dCSA-1 - distance from the anterior nares to cross-selectional area 1 (isthmus nasi), LA - left side of the nose after a decongestant, $L B$ - left side of the nose before a decongestant, $R A$ - right side of the nose after a decongestant, $R B$ - right side of the nose before a decongestant.

Figure 4. Mean distance from the anterior nares to isthmus nasi before and after administration of a decongestant in healthy individuals (with no deviated nasal septum); data stratified by age and sex

est cross-sectional area at their second notch (CSA-1) both in the female and male subpopulations (Table 5). The minimal cross-sectional area (MCA) (or greatest narrowing) of the nasal cavity was at CSA-1 in $76.5 \%$ of females and in $75.5 \%$ of males. CSA- 1 is the notch in the AR curve that corresponds to the region of the nasal valve, where the MCA is generally located. The rest of the study subjects had MCA at $0 \mathrm{~cm}$. Following nasal mucosa decongestion, $70.1 \%$ of examined females and in $73.9 \%$ of examined males showed the lowest values in their AR curves from the left side of the nasal cavity at the second notch (CSA-1). AR curves from the right side of the nasal cavity showed the greatest narrowing at CSA-1 in 68.2\% of females and in $70.2 \%$ of males.

We analysed the possible correlation between subject age and height as well as the possible correlation between rhinometric parameters and subject age and height in both females and males aged 6-18 years. The results in subjects of both sexes under 18 years of age were more homogeneous than the corresponding results from older individuals. The relationship between subject height and age before the age of 18 years was nearly linear. However, it was the subjects' height that showed a slightly better correlation with most of the assessed rhinometric parameters. This was particularly evident in the boys assessed following nasal mucosa decongestion. Determining the exact relationship between subject height and age in the 6-18-year age range helped calculate the average annual rate of growth in boys and girls. The average annual growth was $5.9 \mathrm{~cm}$ in boys aged 6-18 years and $4.2 \mathrm{~cm}$ in girls in the same age brackets. Subject height tends to be slightly better correlated with rhinometric parameters than subject age is, especially in the age group between 6 and 18 years.

\section{Discussion}

The subjective lack of nasal obstruction, although important from a clinical perspective, is not synonymous with the anatomically normal structure of the nasal cavity. Defining a "normal nose" is difficult due to racial, environmental, and developmental differences, which lead to substantial variations both in the structure of the nasal scaffolding and in the condition of the nasal mucosa. Determining whether the examined nose is healthy or not based on physical examination (anterior rhinoscopy) is difficult as it involves the examiner's subjective opinion. This is particularly evident in assessing the inferior 
turbinate for oedema or hypertrophy. This is why studies involving healthy individuals who (subjectively) experience no difficulty while breathing through the nose and have no discernible rhinologic pathologies continue to be of interest and are still being undertaken.

Due to their character, rhinometric examinations can be used to assess individuals of any age [1, 5, 8-11]. The values of MCA and nasal volume reported by Wartelle in young children aged $24-35$ months $(n=16)$ were $0.56 \mathrm{~cm}^{2}$ and $2.14 \mathrm{~cm}^{3}$, respectively; in children aged $36-47$ months $(n=24)$ those values were $0.53 \mathrm{~cm}^{2}$ and $2.59 \mathrm{~cm}^{3}$, respectively; and in children aged $48-60$ months they were $0.58 \mathrm{~cm}^{2}$ and $2.86 \mathrm{~cm}^{3}$, respectively [12]. Studies conducted by Polish researchers in a neonatal population aged $2-4$ days showed the mean MCA of $0.03 \mathrm{~cm}^{3}$ and the nasal volume of $1.19 \mathrm{~cm}^{3}$. Interestingly, Bączek et al. observed no significant differences in the nasal patency in a group of young children due to the physiological phenomenon of the nasal cycle (i.e. alternating partial congestion and decongestion of the nasal cavities). The phenomenon of the nasal cycle is typically present in nearly $80 \%$ of evaluated adults [13].

Riechelmann et al. [14] examined 35 healthy children aged 3 to 6 years. That study showed that a reliable assessment result could be expected in $90 \%$ of the evaluated children. Those authors also observed a correlation between child age and the size of the nasal cavity. They also pointed out limitations of an AR examination, including the fact that CSA values lower than $0.2 \mathrm{~cm}^{2}$ lead to falsely lower nasal volume results beyond that point; as well as the fact that AR offers no possibility of assessing either the location or size of the turbinates. Those authors also reported that nasopharyngeal cavity measurements are affected by soft-palate movements. Another study assessing the nasal cavity in children aged $0-15$ years was conducted in Poland by Bączek and Hassmann-Poznańska [15] in a population of 42 children: group I - 10 children aged 0-1 year, group II -19 children aged 5-10 years, and group III - 13 children aged 11-15 years. That study showed an increase in all assessed parameters from age group to age group. The rhinometry curves in the group of infants (group I), who were examined with the use of a specially adapted nosepiece (mini-probe), showed a single notch, with the combined area for both sides of the nose of 0.18 $\pm 0.04 \mathrm{~cm}^{2}$ (SD = 0.10-0.26) located $0.63 \pm 0.19 \mathrm{~cm}$ (SD $=0.22-1.04$ ) from the anterior nares. The rhinometry curves in groups II and III showed two notches located $0.69-0.79 \mathrm{~cm}$ and $1.90-2.09 \mathrm{~cm}$ from the anterior nares, respectively. In groups II and III (ages 5-15 years) the MCAs were located at the second notch on individual AR curves, and their values were $0.29 \pm 0.12 \mathrm{~cm}^{2}$ in group II and $0.34 \pm 0.11 \mathrm{~cm}^{2}$ in group III. The study by Riechelmann et al. mentioned above also reported MCAs at the second notch in 21 out of 35 evaluated children. AR curves of the remaining 14 children showed the MCA
Table 5. The proportion of subjects (stratified by sex) assessed for CSA-1 and dCSA-1 on either side of the nose before and after administration of a decongestant

\begin{tabular}{|c|c|c|c|}
\hline \multirow[t]{2}{*}{ Parameter } & \multicolumn{3}{|c|}{ Minimum cross-sectional area } \\
\hline & $\begin{array}{l}\text { RB CSA-1 } \\
<\text { CSA-0 }\end{array}$ & $\begin{array}{c}\text { RB CSA-1 } \\
>\text { CSA-0 }\end{array}$ & $N$ \\
\hline Females & $76.5 \%$ & $23.5 \%$ & 306 \\
\hline Males & $75.5 \%$ & $24.5 \%$ & 254 \\
\hline Total study population & $76.0 \%$ & $24.0 \%$ & 560 \\
\hline Parameter & $\begin{array}{l}\text { LA CSA-1 } \\
<\text { CSA-0 }\end{array}$ & $\begin{array}{l}\text { LA CSA-1 } \\
>\text { CSA-0 }\end{array}$ & $N$ \\
\hline Females & $70.1 \%$ & $29.0 \%$ & 283 \\
\hline Males & $73.9 \%$ & $26.1 \%$ & 254 \\
\hline Total study population & $72.4 \%$ & $27.6 \%$ & 537 \\
\hline Parameter & $\begin{array}{c}\text { RA CSA-1 } \\
<\text { CSA-0 }\end{array}$ & $\begin{array}{c}\text { RA CSA-1 } \\
>\text { CSA-0 }\end{array}$ & $N$ \\
\hline Females & $68.2 \%$ & $31.8 \%$ & 305 \\
\hline Males & $70.2 \%$ & $29.8 \%$ & 230 \\
\hline Total study population & $69.1 \%$ & $30.9 \%$ & 535 \\
\hline Parameter & $\begin{array}{l}\text { LB CSA-1 } \\
<\text { CSA-0 }\end{array}$ & $\begin{array}{l}\text { LB CSA-1 } \\
>\text { CSA-0 }\end{array}$ & $N$ \\
\hline Females & $74.6 \%$ & $25.4 \%$ & 299 \\
\hline Males & $77.6 \%$ & $22.4 \%$ & 250 \\
\hline Total study population & $76.0 \%$ & $24.0 \%$ & 549 \\
\hline
\end{tabular}

CSA-O - cross-sectional area at notch 0 along the acoustic rhinometry curve, CSA-1 - cross-sectional area at notch 1 (isthmus nasi) along the acoustic rhinometry curve, $L A$ - left side of the nose after a decongestant, $L B$ - left side of the nose before a decongestant, $R A$ - right side of the nose after a decongestant, $R B$ - right side of the nose before a decongestant.

at the first notch. In adults with no diagnosed nasal pathologies, the MCA is found at the region of the nasal valve, which corresponds to the first AR notch, especially in studies that disregard notch 0 (corresponding to the connection between the anterior nares and the nasal adapter) [14].

Similar studies that used AR to evaluate the size of the nasal cavities in children aged 1-11 years have been conducted by Ho et al. from the University of Hong Kong [16]. Those authors examined a group of 183 Asian children with no diagnosed nasal pathologies and no nasal obstruction. The following parameters were evaluated: MCA at the level of the nasal isthmus, inferior turbinate, posterior nares, and nasopharynx; the distance between MCA and the anterior nares; the length of the nasal cavity (measured from the first notch in the AR curve - which is considered to be the beginning of the curve - to the notch that in researchers' opinion corresponded to the posterior nares); and the volume of the nasal cavity. The mean MCA in the study population was $0.32 \pm 0.13 \mathrm{~cm}^{2}$, and it was located at $1.4 \mathrm{~cm}$ from the beginning of the rhinometry curve. The greatest narrowing of the nasal cavity (MCA) was found to be in the anterior part of the 
nasal cavity. The results of that study are consistent with those reported by Riechelmann et al., who studied a population of Caucasian children from the same age group [14]. The study used AR to evaluate 35 preschool-age children (aged 3-6 years). The obtained mean MCA was $0.29 \pm 0.06 \mathrm{~cm}^{2}$. An analysis of the results of those two studies showed no differences in intranasal structure between Asian and Caucasian preschool children. Analysing the relationship between MCA and subject age, Ho et al. observed that the value of MCA in 1-year-old children is disproportionately large $\left(0.43 \pm 0.25 \mathrm{~cm}^{2}\right)$ in comparison with that in children aged 2-11 years, and thus it was excluded from the analysis. The increase in MCA values over time between the age of 2 and 11 years was 15\% (from $0.27 \mathrm{~cm}^{2}$ to $0.31 \mathrm{~cm}^{2}$ ). The increase in MCA values in this age range was markedly lower than the corresponding increase in height, with the latter at 60\% (from $86.8 \mathrm{~cm}$ in the 2-year-olds to $138.8 \mathrm{~cm}$ in the 11 -yearolds). On the other hand, the increase in nasal cavity volume and length was proportional to the increase in height. Researchers suggest the possibility that turbinate growth in young children is more rapid than the growth of the facial skeleton, which, consequently, reduces the nasal CSA. The analysis was made more difficult due to the small number of evaluated children and the disproportionate size of the compared groups (six 11-year-olds vs twenty-six 2-year-olds).

Hoshino et al. evaluated 171 Japanese children aged 6-14 years for the variability in the effective cross-sectional area (ECSA) and airway resistance depending on subject sex, age, height, and weight. That study enrolled children with no upper airway pathologies and normal nasal patency. Nasal patency was assessed with active anterior rhinometry by measuring airway resistance and indirectly calculating the ECSA. ECSA values were demonstrated to be higher in the group of boys than those in the group of girls. The ECSA increased directly proportionally to subject age, height, and log of weight. Conversely, airway resistance was inversely proportional to the squares of subject weight, height, and age. Analysis of the results indicated that subject height is the best parameter for determining normal airway resistance and ECSA[17].

The increase in nasal parameters in children aged 6-15 was also evaluated by Warren et al. They examined 102 children (using the pressure-flow technique with a nasal mask, while the children breathed through the left and right nasal cavity simultaneously) to determine the mean CSA of the nasal cavity. The study also evaluated the proportion of nasal breathing in different age groups between 6 and 15 years via respiratory inductance plethysmography. The MCA was shown to increase annually by an average of $0.032 \mathrm{~cm}^{2}$, with the value of this parameter of $0.21 \pm 0.05 \mathrm{~cm}^{2}$ at the age of 6 years and $0.46 \pm 0.15 \mathrm{~cm}^{2}$ at the age of 14 years. Also, the use of nasal breathing is becoming more common in children as they grow older. The breathing route in children aged 6-8 years was $40-60 \%$ nasal; children aged $8-12$ years used the nasal route to the extent of $60-80 \%$; and only children over 12 years old were shown to use the nasal breathing route to the extent of over $90 \%$ (at rest). Warren et al. evaluated adults and showed that nasal breathing is compromised if the mean CSA in the nasal cavity is reduced by $33 \%$ from its normal value [18]. The normal MCA was established at $0.6 \mathrm{~cm}^{2}$, whereas values below $0.4 \mathrm{~cm}^{2}$ were found to be associated with partial activation of the oral breathing route in order to reduce upper airway resistance.

The above-mentioned AR studies involving children and adolescents were either conducted in small populations $[13,14]$ or their results were averaged for the entire study population, which fails to reliably represent normal parameters for any individual age group [16]. Other mentioned studies did not use AR, with the CSAs calculated indirectly $[17,18]$. Therefore, the study conducted at our centre focused on tracing selected rhinometric parameters in consecutive paediatric age groups classified into 2-3-year-long intervals. As in the study by Bączek et al. [13], we observed two notches in the segment of the AR curve in children aged 6-15 years, which corresponded to constrictions in the anterior part of the nasal cavity. In children aged 6-8 years, the first notch (notch 0 ) was located at $0.80-0.84 \mathrm{~cm}$ in females and at $0.78-0.86 \mathrm{~cm}$ in males. In 15-16-yearold adolescents, notch 0 on the AR curve was located at $0.75-0.76 \mathrm{~cm}$ in females and at $0.69-0.70 \mathrm{~cm}$ in males. In our study this notch was interpreted as the junction between the anterior nares and the nasal adapter, and it can be found further from the beginning of the AR curves representing smaller nasal cavities. This is associated with technical aspects of an AR examination. This phenomenon was not evident in the studies quoted here as they (for the most part) used average values for the entire study populations. The CSA at notch 0 in 6-8-year-olds was $0.41-0.42$ in females and $0.43-0.45$ in males, whereas in 15-16-year-olds it was $0.61-0.63$ in females and $0.67-0.70$ in males. The second notch in the AR curve (notch 1; CSA-1) corresponded to the site of nasal cavity constriction at the nasal valve. This notch represented the most pronounced narrowing of the nasal cavity and was observed in the majority $(70 \%)$ of subjects. The CSA-1 value in 6-8-year-olds was $0.37 \mathrm{~cm}^{2}$ in females and $0.36-0.40 \mathrm{~cm}^{2}$ in males. Whereas in 15-16-year-olds it was $0.49 \mathrm{~cm}^{2}$ in females and $0.52-0.55 \mathrm{~cm}^{2}$ in males. The distance from the anterior nares to notch 1 (dCSA-1) in 6-8-year-olds was 1.95$2.01 \mathrm{~cm}$ in females and $1.85-1.93 \mathrm{~cm}$ in males, whereas in 15-16-year-old adolescents it was $2.21-2.23 \mathrm{~cm}$ in females and $2.26-2.31 \mathrm{~cm}$ in males. The distances from the beginning of the AR curve to the individual notches measured in our study were very similar to those reported by Bączek et al. However, our study showed a greater 
CSA-1 value (measured at the second notch in the AR curve, which corresponds to the isthmus nasi). Like in our study, Ho et al. considered the first notch in the AR curve to mark the beginning of the nasal cavity. Ho et al. reported the distance from the beginning of the nasal cavity to the area of its greatest constriction as $1.40 \mathrm{~cm}$ (this was a mean distance in children aged 2-11 years). In our study, the corresponding distance (dCSA-1) in 6-8-year-olds was $1.15-1.19 \mathrm{~cm}$ in females and 1.22$1.29 \mathrm{~cm}$ in males. That same distance in 15-16-year-olds was $1.45-1.47 \mathrm{~cm}$ in females and $1.57-1.58 \mathrm{~cm}$ in males. Although these values should not be compared directly, they do fall within a similar range. The lower CSA value (of $0.32 \mathrm{~cm}^{2}$ ) at the nasal valve reported by Ho et al. in comparison to that measured in our study group may be due to the fact that the children examined by Ho were much younger.

The already mentioned study by Warren et al. reported the annual increase in the MCA between the ages of 5 and 16 years as $0.032 \mathrm{~cm}^{2}$. The study used the pressure-flow technique and calculated the MCA indirectly without specifying its location in the nasal cavity. In our study, the calculated mean annual increase in the CSA-1 value (at the nasal valve) between the ages of 7 and 17 years was based on AR measurements. We observed a relatively steady increase in CSA-1 values across all age groups. The total increase in CSA-1 from age 7 to age 17 was from $0.12 \mathrm{~cm}^{2}$ to $0.15 \mathrm{~cm}^{2}$ in females and from $0.17 \mathrm{~cm}^{2}$ to $0.24 \mathrm{~cm}^{2}$ in males, yielding an annual increase of $0.013 \mathrm{~cm}^{2}$ and $0.020 \mathrm{~cm}^{2}$, respectively. The discrepancy in the calculated annual CSA increase rates between Warren's and our study is most likely due to the fact that Warren calculated the increase of an indirectly obtained MCA, which in reality does not have to correspond to the nasal isthmus (nasal valve), whose location can be fairly precisely identified via AR.

\section{Conclusions}

Nasal cavity volumes, as measured via AR, increased with the subject age. Larger nasal cavity volumes were observed in males. The difference between the size of male and female nasal cavities increased with the age and reached statistical significance over time.

\section{Conflict of interest}

The authors declare no conflict of interest.

\section{References}

1. Straszek SP, Moeller A, Hall GL, et al. Reference values for acoustic rhinometry in children from 4 to 13 years old. Am J Rhinol 2008; 22: 285-91.

2. Samolinski BK, Grzanka A, Gotlib T. Changes in nasal cavity dimensions in children and adults by gender and age. Laryngoscope 2007; 117: 1429-33.
3. Clement PAR, Gordts F. Consensus report on acoustic rhinometry and rhinomanometry. Rhinology 2005; 43: 169-79.

4. Grymer LF. Clinical applications of acoustic rhinometry. Rhinol Suppl 2000; 16: 35-43.

5. Melo AC, de Oliveira de Camargo Gomes A, Santos Cavalcanti A, et al. Acoustic rhinometry in mouth breathing patients: a systematic review. Braz J Otorhinolaryngol 2015; 81: 212-8.

6. Vogt K, Bachmann-Harildstad G, Lintermann A, et al. The new agreement of the international RIGA consensus conference on nasal airway function tests. Rhinology 2018; 56-2: $133-43$.

7. Gotlib T, Samoliński B, Arcimowicz M. Spontaneous changes in the nasal valve site dependent on the nasal cycle. Am J Rhinol 2000; Program and abstracts "The Nose 2000 and beyond": A-209.

8. Hilberg O. Objective measurement of nasal airway dimensions using acoustic rhinometry: methodological and clinical aspects. Allergy 2002; 57 Suppl. 70: 5-39.

9. Hilberg O, Pedersen OF. Acoustic rhinometry: recommendations for technical specifications and standard operating procedures. Rhinol Suppl 2000; 16: 3-17.

10. Qian W, Chen W, Chen JM, et al. Acoustic rhinometry in preschool children. Otolaryngol Head Neck Surg 2007; 137: 39-42.

11. Liukkonen K, Virkkula P, Pitkäranta A. Acoustic rhinometry in small children. Rhinology 2006; 44: 160-3.

12. Wartelle S, Simon F, Louis B, et al. Endonasal measurements by acoustic rhinometry in children: a preliminary study. Int J Pediatr Otorhinolaryngol 2018; 107: 93-6.

13. Bączek M, Hassmann-Poznańska E, Alfier M, et al. Acoustic rhinometry assessment of the nasal cycle in neonates. Acta Otolaryngol 2001; 121: 301-4.

14. Riechelmann H, Rheinheimer MC, Wolfensberger M. Acoustic rhinometry in pre-school children. Clin Otolaryngol 1993; 18: 272-7.

15. Bączek M, Hassmann-Poznańska E. Nasal airway dimensions in children, measured by acoustic rhinometry. New Medicine 1999; 3: 4-5.

16. Ho WK, Wei WI, Yuen AP, et al. Measurement of nasal geometry by acoustic rhinometry in normal-breathing Asian children. J Otolaryngol 1999; 28: 232-7.

17. Hoshino T, Togawa K, Nishihira S. Statistical analysis of changes of pediatric nasal patency with growth. Laryngoscope 1988; 98: 219-25.

18. Warren DW, Hairfield M W. The relationship between nasal airway size and nasal - oral breathing. Am J Orthodont Dentofac Orthop 1988; 93: 289-93. 